\title{
Urethral Myiasis
}

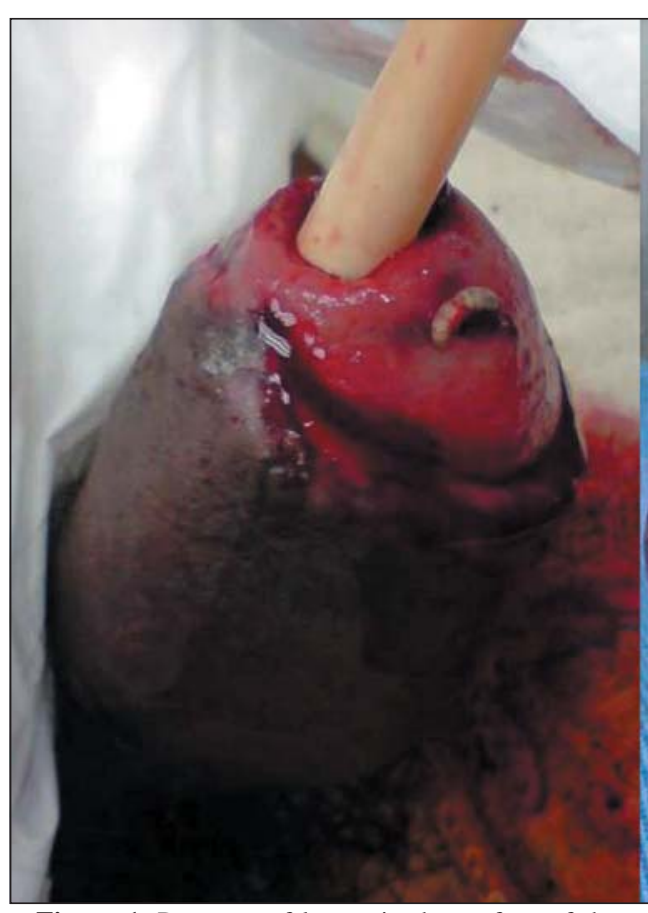

Figure 1. Presence of larvae in the surface of the urethral catheter, demonstrating the possible form of migration through the urethra

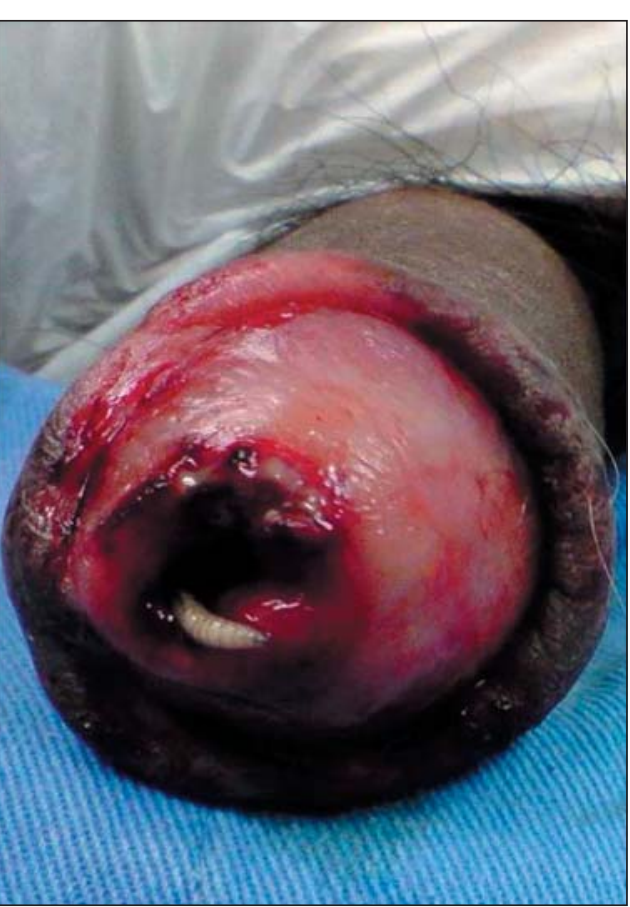

Figure 2. Withdrawal of the urinary catheter showing the remaining larvae.

Urethral myiasis is exceptionally rare, even in sites usually protected by clothes, inaccessible for the flies. Urogenital myiasis is usually associated with patients in poor general condition, with low mobility and ulcerating lesions [1]. It could be external or internal, and the invasion for the maggot could be obligatory, facultative, and sometimes accidental.

Many species of dipterous flies among the genera Chrysomyia and Cochliomyia have been reported to be the most important obligatory myiasis producers among humans and/or domestic animals [2].

The explanation of the urinary myiasis in the patient was that the flies deposited their eggs around the catheter or genital orifice and after hatching in a few hours, the larvae may have migrated through the urethra where they matured [1,3,4].

Signs and symptoms related are: haematuria, bladder irritated symptoms, pruritus, dysuria, fever and elimination of larvae in urine. Severity of myiasis depends on the location of the infestation, lesions and tissue inflammation [1].

According to Gopalakrishnan et al.[2], a progressive and continous necrosis of muscles occur associated with larval growth and invasion. The pathogenicity results from inflammation and toxin secreted by the larvae which prevents healing.

The treatment involves the use of several antiseptics, suffocating and mercury [5]. Such substances were used in the form of lavage, inhalations, instillations, and in smaller number of cases, systematic way. Some studies show the use of Ivermectin to eradicate the larvae of myiasis cavity without endangering the patient [6]. A broad antibiotic cover is recommended to prevent secondary infections.

Daniel K. Abe, Rafael T.L. Rosa, Marcos F. Dall' Oglio, Michele H. Fróes, Bruno C. Almeida and Luiz A.M. Said abe.daniel@gmail.com

\section{References}

1. Hyun D.Y., Cain M.P., Blue-Hnidy D.E., Conway JH. Urinary myiasis associated with ureteral stent placements. Pediatr Infect Dis J 2004;23:179-81.

2. Gopalakrishnan S., Srinivasan R., Saxena S.K., Shanmugapriya J. Myiasis in different types of carcinoma cases in southern India. Indian J Med Microbiol 2008;26:189-92.

3. Meinhardt W., Disney R.H. Urogenital myiasis caused by scuttle fly larvae (Diptera: Phoridae). Br J Urol 1989;64:547-8.

4. Passos M.R.L, Barreto N.A., Varella R.Q. et al. Penile myiasis: a case report, Sex Transm Infect 2004;80:183-4.

5. VWadhwa P., Kharbanda S., Rai B. Urogenital Myiasis due to Chrysomyia Bezziana. Indian Journal of Medical Microbiology 2006;24(1):70-1.

6. Ribeiro FAQ, Pereira CSB, Alves A, Marcon MA. Tratamento da miíase humana cavitária com ivermectina oral. Rev Brás Otorrinolaringol 2001;67:755-761.

The Brazilian Journal of Infectious Diseases (www.bjid.com.br) 2009;13(3):253.

(C) 2009 by The Brazilian Journal of Infectious Diseases and Contexto Publishing. All rights reserved. 